05.3;06.4

\title{
Возможности экранной защиты космических объектов от удлиненного ударника со скоростью $7-11 \mathrm{~km} / \mathrm{s}$
}

\author{
() Б.В. Румянцев ${ }^{1}$, И.В. Гук ${ }^{2}$, А.И. Козачук ${ }^{1}$, А.И. Михайлин ${ }^{2}$, С.И. Павлов ${ }^{1}$, М.В. Сильников ${ }^{2}$ \\ ${ }^{1}$ Физико-технический институт им. А.Ф. Иоффре РАН, Санкт-Петербург, Россия \\ 2 ОАО „НПО „Спецматериалы“, Санкт-Петербург, Россия \\ E-mail: brum@mail.ioffe.ru
}

Поступило в Редакцию 24 декабря 2020г.

В окончательной редакции 24 декабря 2020 г.

Принято к публикации 8 января 2021 г.

\begin{abstract}
Исследуется поражение преграды из дюраля при воздействии алюминиевой струи (аналог фрагмента техногенного мусора) со скоростью $7-11 \mathrm{~km} / \mathrm{s}$ при наличии металлических экранов из меди и алюминия. Выделена доля эффективности экранной защиты, определяемая разлетом частей разрушенного ударника между экранами. Определено повышение эффективности экранной защиты за счет фазовых переходов взаимодействующих материалов ударника и экрана.
\end{abstract}

Ключевые слова: экранная защита, техногенный мусор, плавление, испарение.

DOI: 10.21883/PJTF.2021.08.50846.18672

Действие экранной защиты (ЭЗ) космических аппаратов [1] основано на предварительном разрушении и рассеивании высокоскоростного компактного ударника между экранами и преградой. В случае алюминиевого ударника эффективность ЭЗ возрастает с увеличением скорости ударника до $7 \mathrm{~km} / \mathrm{s}$ [2], что обеспечивает полное разрушение компактного ударника при взаимодействии с экранами. Фрагменты ударника с радиальной составляющей от оси удара рассеиваются в межэкранном пространстве, поглощаются экранами и исключаются из воздействия на преграду (космический аппарат). При дальнейшем повышении скорости компактного ударника $(7-10 \mathrm{~km} / \mathrm{s})$ отмечалось различие в характере повреждений преграды при сохранении баллистического предела из-за плавления ударника [3].

В настоящей работе исследуются факторы, влияющие на эффективность двухэкранной защиты с фиксированными поверхностной плотностью экрана $8.9 \mathrm{~kg} / \mathrm{m}^{2}$ и расстоянием $2 \mathrm{~cm}$ между экранами и преградой (рис. 1) от ударника удлиненной формы при скоростях, характерных для космического мусора в околоземном космическом пространстве.

Для формирования удлиненного ударника в работе применялись кумулятивные заряды (КЗ) 1 с массой взрывчатого вещества $40 \mathrm{~g}$, содержащие металлическую воронку 2 с полным углом при вершине $A$ от 60 до $20^{\circ}$, толщиной $0.08 \mathrm{~cm}$ и диаметром в основании $2 \mathrm{~cm}$. Кумулятивные заряды позволяли получать металлические струи (МС) со скоростями до $11 \mathrm{~km} / \mathrm{s}$, которые приняты аналогами удлиненных ударников. В отличие от широко распространенных КЗ с медной облицовкой $[4,5]$ в работе применялись КЗ с воронкой из алюминиевого сплава. С использованием преграды 4 из дюраля АМГ6 (рис. 1) моделировалось взаимодействие фрагмента космического мусора с ЭЗ космического аппарата. Протяженная преграда полного поглощения МС позволяла зафиксиро- вать остаточную энергию и последствия взаимодействия ударника с экранами, а также предельные параметры поражения.

Далее анализируются результаты с экранами из дюраля АМГб [2] и меди, так как в работах [6,7] было показано, что защитная способность ЭЗ растет при
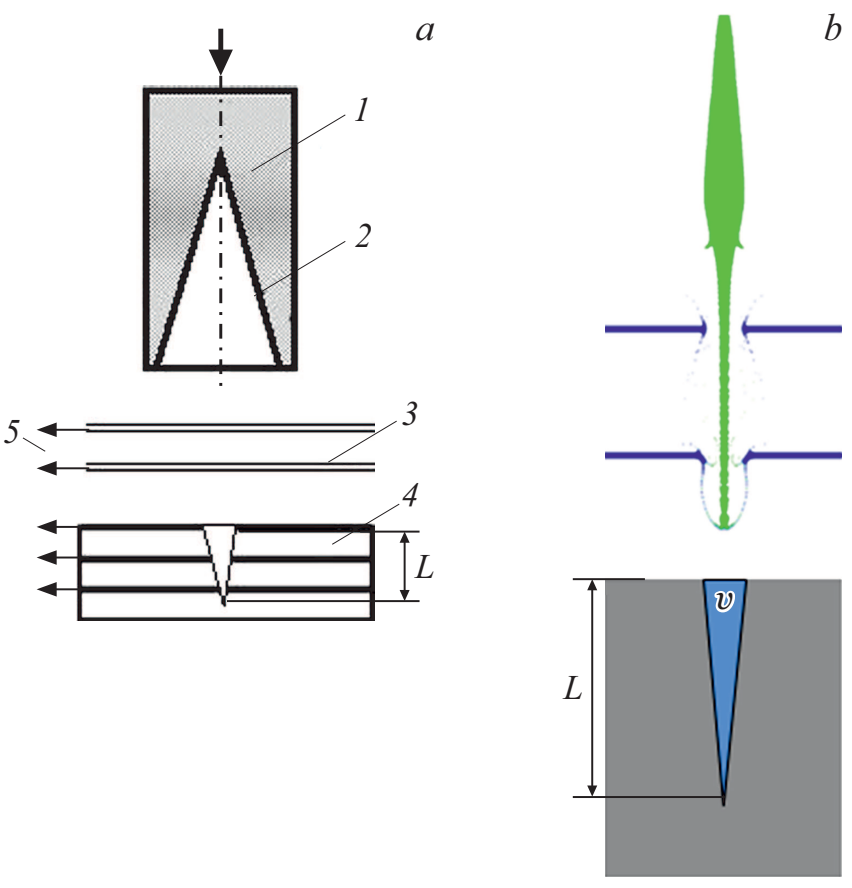

Рис. 1. $a-$ схема эксперимента. $1-$ кумулятивный заряд, 2 - металлическая воронка, 3 - экраны, 4 - преграда, 5 - контактные датчики измерения времени. Промежутки между зарядом, экранами и преградой составляли $0.02 \mathrm{~m}$, давление воздуха $1 \mathrm{kPa} . b$ - численное моделирование пробития экранов и схема каверны в преграде. Параметры поражения: глубина $(L)$ и объем $(v)$ каверны. 

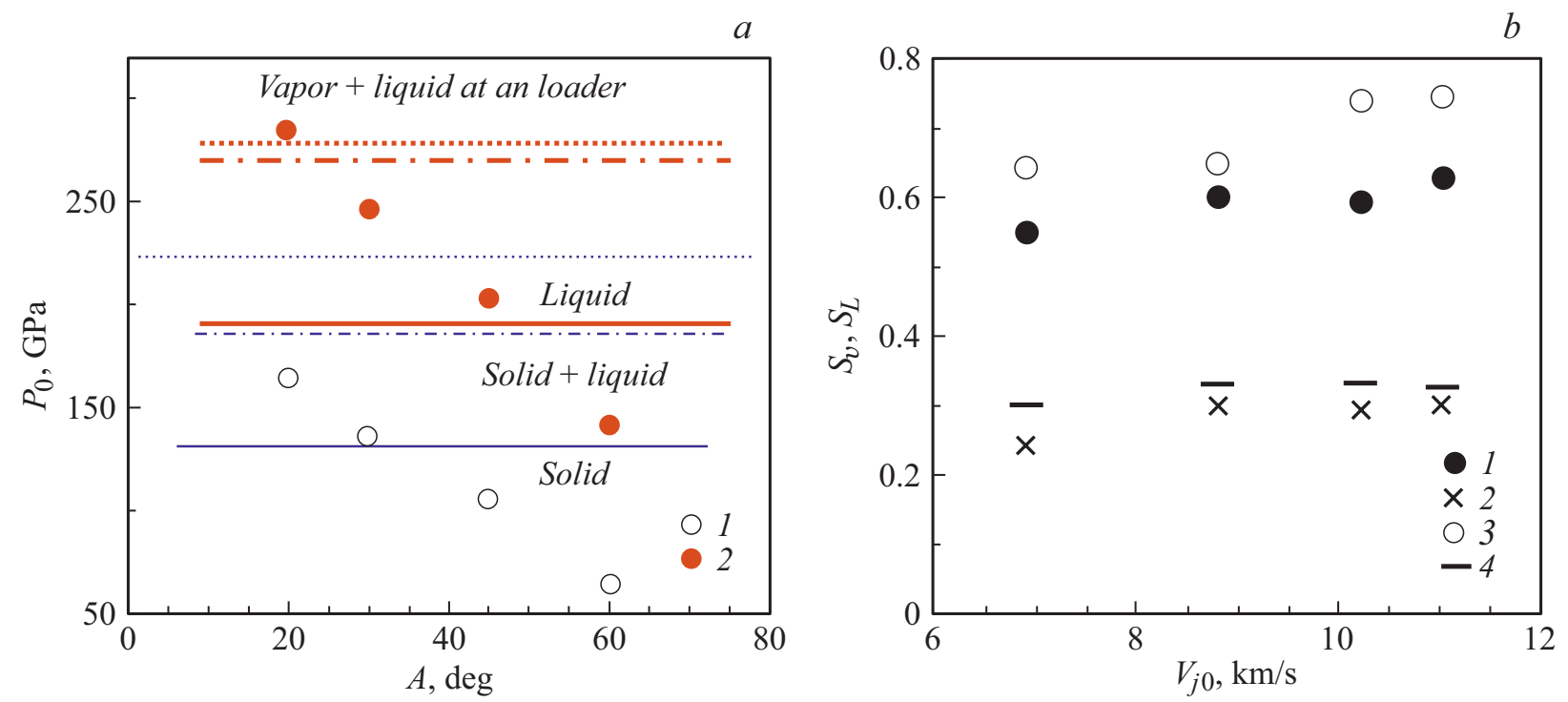

Рис. 2. $a$ - начальные давления взаимодействия алюминиевых струй, сформированных КЗ с разными углами $A: 1-$ с преградой из дюраля $\left(P_{0 \mathrm{Al}-\mathrm{Al}}\right), 2-\mathrm{c}$ преградой из меди $\left(P_{0 \mathrm{Al}-\mathrm{Cu}}\right)$. Тонкие линии - разделения фазового состояния в дюрале АМГ6, жирные - в меди. $b$ - относительное снижение объема $(1,3)$ и глубины $(2,4)$ каверны в преграде после двух экранов: из дюраля $(1,2)$ и меди $(3,4)$.

Параметры алюминиевых струй и каверны в преграде АМГб в зависимости от угла $A$ конической воронки из АМГ6 кумулятивного заряда

\begin{tabular}{c|c|c|c|c|c|c}
\hline $\begin{array}{c}A, \\
\mathrm{deg}\end{array}$ & $\begin{array}{c}V_{j 0}, \\
\mathrm{~km} / \mathrm{s}\end{array}$ & $\begin{array}{c}L, \\
\mathrm{~cm}\end{array}$ & $\begin{array}{c}v, \\
\mathrm{~cm}^{3}\end{array}$ & $\begin{array}{c}d_{j}, \\
\mathrm{~cm}\end{array}$ & $\begin{array}{c}P_{0 \mathrm{Al}-\mathrm{Al}}, \\
\mathrm{GPa}\end{array}$ & $\begin{array}{c}P_{0 \mathrm{Al}-\mathrm{Cu}}, \\
\mathrm{GPa}\end{array}$ \\
\hline 20 & 11.6 & 11.2 & 14 & 0.07 & 163 & 285 \\
30 & 10.2 & 11.3 & 11 & 0.07 & 135 & 246 \\
45 & 8.8 & 10 & 9.6 & 0.08 & 104 & 202 \\
60 & 6.9 & 9.5 & 7.6 & 0.09 & 88 & 140
\end{tabular}

Пр имечание. $V_{j 0}-$ скорость головной части кумулятивной струи, $L$ и $v$ - глубина и объем каверны в преграде без экранной защиты, $d_{j}-$ средний диаметр кумулятивной струи.

испарении взаимодействующих материалов ударника и экрана. В частности, для ударно-сжатой меди испарение наступает при разгрузке от давления на ударной адиабате более $270 \mathrm{GPa}$ [8]. Аналогичное увеличение защитной способности должно наблюдаться и для алюминиевой струи, если в области взаимодействия будут достигнуты давления на ударной адиабате алюминия порядка $220 \mathrm{GPa}$ [9]. При изоэнтропической разгрузке области взаимодействия часть ударно-сжатого жидкого алюминия будет испаряться.

Кроме того, в работе [10] отмечалось, что при скорости внедрения $>9 \mathrm{~km} / \mathrm{s}$ алюминиевой струи в алюминиевую преграду наблюдаются последствия дестабилизации внедрения начальной скорости $\mathrm{MC}$, связанной с плавлением алюминия на начальной стадии внедрения.

В таблице приведены экспериментальные значения $V_{j 0}$ начальной скорости $\mathrm{C}$, а также параметры поражения (глубина пробития $L$ и объем $v$ каверны) в преграде из дюраля АМГ6 при различных углах алюминиевой воронки в отсутствие экранов (рис. 1). Дополнительно в таблице отображены начальные давления взаимодействия алюминиевой струи с дюралевой $\left(P_{0 \mathrm{Al}-\mathrm{Al}}\right)$ и медной $\left(P_{0 \mathrm{Al}-\mathrm{Cu}}\right)$ преградами. Начальные давления в зоне взаимодействия определялись методом торможения $[4,11]$ по пересечению ударной адиабаты экрана (преграды) и отраженной ударной адиабаты алюминиевого ударника.

На рис. 2, а представлены уровни давлений, отвечающие границам области плавления на ударной адиабате и значениям, при которых разгрузка ударно-сжатой жидкости приводит к взрывному испарению. Из сопоставления с начальным давлением взаимодействия ударника с экраном (преградой) видно, что кумулятивные струи с разными экранами могут реализовывать на начальной стадии взаимодействия фазовые переходы: плавление алюминия струи и экрана, плавление и испарение части медного экрана. Фазовые переходы с увеличением удельного объема будут оказывать дестабилизирующее влияние на дальнейшее внедрение МС в преграду $[10,12]$.

В настоящей работе по изменению параметров поражения преграды после ЭЗ в зависимости от начальной скорости удлиненного ударника (MC) предпринята попытка:

- определить эффективность действия экранной защиты за счет механического разрушения, диспергирования и рассеивания части удлиненного ударника в межэкранном пространстве;

- выделить влияние фазовых переходов, возникающих при взаимодействии высокоскоростного ударника с экраном, на поражение преграды.

Эффективность ЭЗ оценивалась по относительному снижению параметров поражения преграды по глубине 


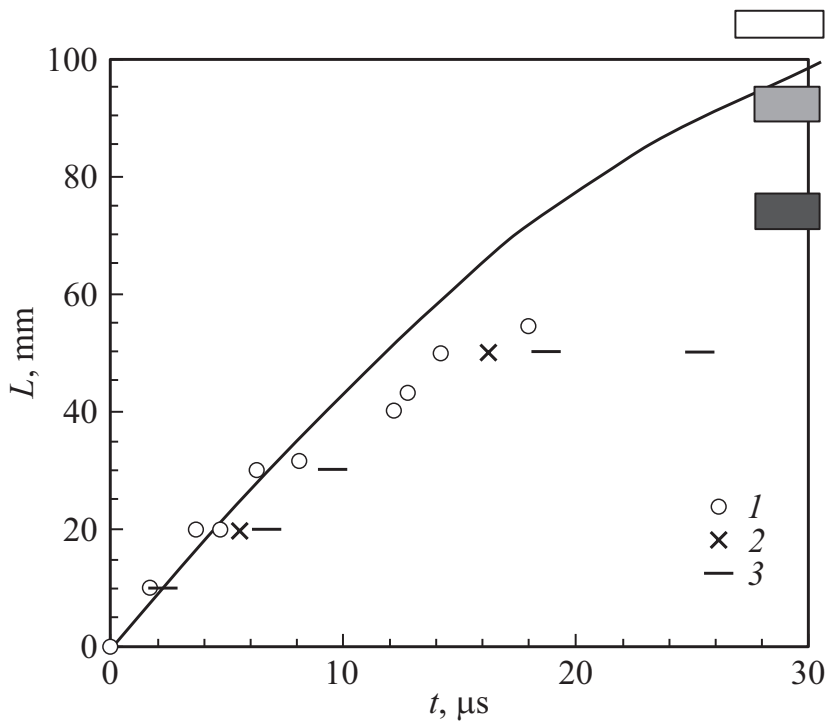

Рис. 3. Траектории внедрения кумулятивной струи от КЗ с $A=30^{\circ}$ после экранов в преграду АМГ6. Символы измеренные времена внедрения в преграду: без экранов (1), с экранами из дюраля (2) и меди (3). Прямоугольники расположены на уровне конечного пробития: светлый - при отсутствии экранов, темный - при наличии медных экранов, серый - c равной поверхностной плотностью экранов из дюраля.

$\left(S_{L}\right)$ и объему $\left(S_{v}\right)$ :

$$
S_{L}=1-L_{+} / L, \quad S_{v}=1-v_{+} / v
$$

где $L_{+}$и $v_{+}$- глубина и объем каверны в преграде при наличии экранов, $L$ и $v-$ глубина и объем каверны в преграде при отсутствии экранов.

На рис. 2, $b$ приведены экспериментальные данные по относительному снижению параметров поражения преграды 4 (см. рис. 1) с экранами из дюраля АМГ6 или меди МТ1. Видно, что для Э3 из дюраля характерно малое изменение эффективности за счет диспергирования и рассеивания между экранами по мере увеличения скорости удлиненного ударника в диапазоне $7-11 \mathrm{~km} / \mathrm{s}$. Наблюдаемое увеличение эффективности ЭЗ с медными экранами на $10-15 \%$ связано с испарением меди и алюминия в зоне взаимодействия ударника и экрана при начальной скорости $>9 \mathrm{~km} / \mathrm{s}$. Влияние плавления слабо проявляется ввиду незначительного изменения удельного объема взаимодействующих материалов.

Измерения траектории внедрения удлиненного ударника (алюминиевой струи) в преграду после ЭЗ (рис. 3) показывают, что взаимодействие с экранами не сводится только к исключению фрагментов ударника при указанном взаимодействии. Скачкообразный характер внедрения в преграду [6] по сравнению с внедрением при отсутствии экранов свидетельствует о дестабилизации МС от локального взаимодействия с экранами.

Увеличение эффективности ЭЗ наблюдается при скоростях, когда в области взаимодействия ударник-экран реализуются давления фазовых переходов. Необходимым условием также является превышение времени пролета удлиненного ударника через экран над временем схлопывания расширяющихся материалов фазовых превращений ударника и экрана (см. рис. $1, b$ ). Обратная радиальная реакция в виде импульса схлопывающихся материаов возмущает последующие участки удлиненного ударника, дестабилизируя дальнейшее его внедрение в преграду.

Таким образом, при постановке эксперимента, моделирующего поражение осколком техногенного „мусора“ преграды, защищенной экранами, определены:

- уровень снижения параметров поражения за счет разрушения и рассеивания удлиненного ударника на двухэкранной защите (для экранов из дюраля АМГб уровень снижения составляет $\sim 30 \%$ по глубине и $\sim 60 \%$ по объему относительно поражения преграды без экранной защиты);

- увеличение эффективности экранной защиты за счет частичного испарения ударника и медного экрана, которое при скоростях столкновения более $9 \mathrm{~km} / \mathrm{s}$ coставляет $10-15 \%$.

\section{Финансирование работы}

Работа выполнена при финансовой поддержке Российского фонда фундаментальных исследований в рамках научного проекта № 18-08-00487/18.

\section{Конфликт интересов}

Авторы заявляют, что у них нет конфликта интересов.

\section{Список литературы}

[1] F. Whipple, Astron. J., 52 (1161), 131 (1947).

[2] IADC-04-03 v. 7. Protection manual (2014).

[3] A.J. Piekutowski, K.L. Poormon, Procedia Eng., 58, 642 (2013). DOI: 10.1016/j.proeng.2013.05.074

[4] Физика взрыва, под ред. Л.П. Орленко (Физматлит, М., 2002), т. 2.

[5] C. Wang, J. Ding, H. Zhao, Defence Sci. J., 65 (4), 279 (2015). DOI: $10.14429 / \mathrm{dsj} .65 .8648$

[6] B.V. Rumyantsev, I.V. Guk, A.I. Kozachuk, A.I. Mikhaylin, S.I. Pavlov, M.V. Silnikov, Acta Astron., 163 (Pt A), 73 (2019). https://doi.org/10.1016/j.actaastro.2019.03.065

[7] B.V. Rumyantsev, A.I. Mikhaylin, Acta Astron., 109, 166 (2015). DOI: 10.1016/j.actaastro.2014.11.040

[8] В.Е. Фортов, И.В. Ломоносов, УФН, 184 (3), 231 (2014).

[9] Д.В. Минаков, Расчет термодинамических свойств плотной плазмы металлов методом функционала плотности и квантовой молекулярной динамики, Канд. дис. (ОИВТ РАН, М., 2015), с. 96.

[10] http://www.ihed.ras.ru/rusbank/

[11] Б.В. Румянцев, И.В. Гук, А.И. Козачук, А.И. Михайлин, С.И. Павлов, М.В. Сильников, Письма в ЖТФ, 46 (9), 25 (2020). DOI: 10.21883/PJTF.2020.09.49368.18229

[12] Б.В. Румянцев, С.И. Павлов, Письма в ЖТФ, 46 (17), 10 (2020). DOI: 10.21883/PJTF.2020.17.49885.18363 